\title{
Sexual Dysfunction and its Associated Factors in Breast Cancer Patients After Mastectomy
}

\author{
Samira Abdollahi Chirani, ${ }^{1}$ Forouzan Elyasi, ${ }^{2,3,}$ and Bahram Mirzaian ${ }^{4}$ \\ ${ }^{1}$ Department of Psychology, Sari Branch, Islamic Azad University, Sari, IR Iran \\ ${ }^{2}$ Department of Psychiatry, Collage of Medicine, Mazandaran University of Medical Sciences, Sari, IR Iran \\ ${ }^{3}$ Psychiatry and Behavioral Sciences Research Center, Addiction Institute, Mazandaran University of Medical Sciences, Sari, IR Iran \\ ${ }^{4}$ Department of Psychology, Sari Branch, Islamic Azad University, Sari, IR Iran \\ "Corresponding author: Forouzan Elyasi, Psychiatry and Behavioral Siences Research Center, Addiction Institute, Mazandaran University of Medical Sciences, Psychiatric \\ Center and Zare, Sari 5 km Road, Neka, Sari, IR Iran. Tel: +98-1133285109, E-mail: forouzan.el@gmail.com
}

Received 2015 July 10; Revised 2016 July 15; Accepted 2016 September 23.

\begin{abstract}
Background: Sexual function refers to a major aspect of health affecting the quality of life in breast cancer patients. Sexual dysfunction (SD) creates high psychological pressures.

Objective: The current research aimed to investigate the frequency of SD and its associated factors in post-mastectomy women. Materials and Methods: The research was a cross-sectional study. Sampling was according to the convenience method. The study was conducted on the women referring to the oncology ward of Tooba post-specialized clinic at Imam Khomeini hospital affiliated to Mazandaran University of Medical Sciences. In order to collect data, the demographic characteristics questionnaire and Female Sexual Function Index (FSFI) questionnaire were filled out by the patients. Descriptive statistics, Pearson and Spearman correlation methods in SPSS 16 were employed to analyze the data.

Results: The mean age of 104 participants in this study was $47.33 \pm 9.03$ years and 91 patients (87.5\%) diagnosed with SD. The highest frequency was related to desire and arousal disorders (69.2 and 64.4\%, respectively) and the lowest to sexual satisfaction disorder (26.9\%). The correlation test results indicate that there was a positive significant relationship between income and sexual function at the confidence level of $95 \%(r=0.20, \mathrm{P}=0.05)$.

Conclusions: High outbreak of SD in these patients suggest that the therapists involved in oncology should ask the patients about their sexual problems and do thorough evaluations; in addition to guide the patients, they should provide them with required training in order to enable them to manage these problems .
\end{abstract}

Keywords: Breast Cancer, Sexual Dysfunction, Women

\section{Background}

Breast cancer is of the most critical factors threatening women's physical and psychological health. Due to its high outbreak, it affects women more than the other cancers psychologically and emotionally (1). Around the world, breast cancer imposes a heavy burden on the health system and it is the most common cancer among either high or low-classes women. Breast cancer affliction among Iranian women has been reported 5.27 out of 100,000 cases. Also annually more than 1000 new cases of breast cancer are detected in Iran, 7778 cases of which are women (2). According to Iran cancer registration report in 2009, 7582 cases of breast cancer have been identified among Iranian women whose peak age was 50 - 55 years old and the standardized age outbreak has been reported 28.25\% /1000 women .Based on the records of the center for disease control of the ministry of health and medical education, breast cancer among Iranian women has been 6975 cases in 2007. In Mazandran province, breast cancer is taken as the first common cancer in women with age specific rate of 24.9 and crude incidence rate of 18.92 that included 267 people (3). Sexuality and sexual satisfaction optimally play a definite role in human character development so that separating these sexualities from every human's behavior is not possible. Sexual matters are firstly ranked in terms of importance in the married life and adjustability in sexual relationships; its appropriateness and balance among couples is among the most important causes behind the success and prosperity of a married life (4). The prevalence of the most common sexual problems reported in these patients following cancer treatment compared to the public population which generally has a higher percentage especially relates to painful intercourse (dyspareunia) and vaginismus (35\% - 38\%) (5).

Chemotherapy, hormone therapy, or ovarian suppression born permanent ovary failure led to in the reduction in estrogen and testosterone levels (the hormones playing decisive role in sexual function). Lack of estrogen accompanies with sexuality and sexual response drop and atro- 
phy and dryness can bring about pain in intercourse (68). It seems that psychological complications have affected women's sexual function more that the physiologic ones since in the majority of the published studies ,the most common sexual issue has been related to sexuality/sexual arousal dimension. This dimension mainly reflects psychological conditions of patients while areas like sexual arousal, vaginal moisture, and sexual pain stem from physiological conditions causes (9).

Cancer post-treatment emotional effects can interfere in the sexual appeal and feeling. The issues involved in the first year of cancer diagnosis include sadness and depression, being concerned about changes, stress related to the partner, reduced self-confidence due to bad feelings and the point that she cannot play her routine roles in family and workplace (10). Because of body stamina drain, dropped capability to run daily chores, patient's hospitalization and finally, the imposed depression, cancer can play a significant role in creating sexual nuisances (11). The research by Anllo (12) and Bakewell and Volker (13) suggested that the trauma resulting from cancer diagnosis and treatment has a great effect on the psychological, physical function and communications of the person in marital life. Schover (7) has reviewed many studies on mastectomy-influenced marital relations, mental and psychological consequences, number of intercourses, and sexual disorders outbreak, showing $26 \%$ of women are seeking cancer born sexual function disorder surgeries (14). Considering the type of surgery, despite some controversial results (15-17), a growing body of evidence indicates that body image in a developing state is significantly better in women undergoing breast conserving surgery (in contrast to mastectomy) $(18,19)$.

In many studies performed on breast cancer stricken patients, the number of samples has been few or retrospective without a control group. However, a number of them suggest that almost all women experience some problems in their sexual function after breast cancer treatment (20). There is no consensus about the effect of gap between surgery and sexual intercourse resumption (15). Though, some other ones have discovered longer delay with higher chance of SFD (21). Regarding the above discussions and high breast cancer prevalence among the women in society as well as very limited studies about sexual disorder in Iranian patients and on the one hand, according to the cultural matters, it seems that sexual disorder rate is reported less than its real rate. It is obvious that the health personnel, if are aware, can provide new treatment and consulting interventions in order to promote the mentioned patients' life quality. In addition, it helps the patient make efforts to uplift her life quality in case of being purposeful to return to the usual activities as much as possible.
Islam- the religion of the vast majority of Iranian people- is a logically welcome religion toward sexual relations, but social attitudes about sex are widely different and sometimes look to some extent as a taboo, thus it is not often-convenient to talk directly about sexual relations in Iranian population. Sexual health is an important, but often neglected component of cancer care. A few studies have reported the prevalence of sexual function among Iranian breast cancer patients so far. Women with breast cancer in Iran are usually younger than their western counterparts and thus might report different experiences. Hence, the present Study aimed to: 1-Determine the prevalence of sexual problems in women with breast cancer after mastectomy, and 2- Investigate the influence of cancer-related factors on female sexuality.

\section{Materials and Methods}

The present research was a cross-sectional study. The statistical population was composed of female with breast cancer during postoperative period referring to the oncology ward of Tooba post-specialized clinic in Imam Khomeini hospital affiliated to Mazandaran University of Medical Sciences for treatment. The inclusion criteria were breast cancer diagnosis (at every stage), being married, not having any other known malignancy or psychological disease, and the surgeries with the post-interval of at least 6 months. The sampling was according to the convenience method. During a four-month follow-up from June 2014 to September 2014, considering the repetition of samples at the end of the period and no new referring case, 33 samples were excluded due to being single, surgical record less than 6 months and a disease history like diabetes and anemia (exclusion criteria). The sample size was estimated based on a single proportion design. Finally, 104 patients holding the inclusion criteria included in the research; having given a written consent, they were put under the study.In order to collect data, demographic characteristics questionnaire was filled out by the patients and women's sexual function was analyzed using the questionnaire of female sexual function index (FSFI). This questionnaire covered 19 questions about sexuality, arousal, vaginal lubrication, orgasm, pain and sexual satisfaction. Scores of the six domains were summed to obtain the total scale scores. For individual domain scores, the scores of all items that comprise the domain were multiplied by the domain factor, where higher scores indicate less function. Higher scores of the FSFI indicate fewer problems about sexual function and lower scores indicate more problems in female sexual function. The cutoff score of Persian version has been determined as 28 or less, given the maximum real positive 
and real negative. The cutoffs of sexual pain, sexual satisfaction, orgasm, vaginal lubrication, sexual arousal and desire dimensions are 3.8, 4.8, 7.3, 4.3,3.3, and 3.3, respectively (22). This tool recognized as Female Sexual Function Index was first developed by Rosen et al. Overall test retest reliability coefficients in the original form of questionnaire were high for each form of the individual domains ( $\mathrm{r}=0.79$ to $r=0.86)$. Cronbach's alpha values for internal consistency was also high $(\geq 0.82)$. Good construct validity was demonstrated (23) and its reliability has been confirmed as 0.82 . In Iran, its reliability and validity have been verified by Mohammadi et al. The overall test-retest reliability coefficients were high for each domain $(\mathrm{r}=0.73$ to 0.86$)$ and the range of internal consistency was acceptable $(\alpha=0.72$ to $\alpha=0.90)(22)$. The internal consistency of the total scale questions of the case group, control group and all subjects has been obtained as 0.85 or higher, indicating the tool's good reliability.

Analysis was performed using SPSS statistical software (version 16) in descriptive and analytical levels to detect the relation of demographic and clinical characteristics of the patients with SD using test. Student t-test and $\mathrm{X}^{2}$ were used to detect the association between demographic and clinical characteristics of the patients. The level of significance was set at $\mathrm{P}<0.05$.

\section{Results}

The mean age of the participants was 47.33 years (standard deviation: \pm 9.03 ) with the range of $27-71$. The patients mean score in terms of FSFI questionnaire was obtained as $\mathbf{2 1 . 0 5}$ with a standard deviation of 7.9.

$62.5 \%$ (65 cases) of the participants lived in rural areas and the rest (37.5\%) in urban areas. Analyzing the participants' education, as depicted in Table 1, showed that the majority of the participants (73.1\%) had high school diploma or under-diploma degrees. Based on the results, none of them had studied in the graduate level. In terms of income level, the results revealed that the income of $38.5 \%$ ranged from 501,000 to $1,000,000$ tomans. $82 \%$ of the participants had no record of psychologist visit (Table 1 ).

The findings derived from the study imply that $78.5 \%$ of the women had SFD. The survey on sexual function dimensions showed that the most frequent disorder was observed in sexuality and arousal aspects (covering 69.2 and $64.4 \%$ of the patients). The result showed that the patients were better in sexual satisfaction function aspect than the other ones, while the lowest disorder $(26.9 \%$ of the patients) was in the satisfaction domain (Table 2).

In analyzing the sexual function and age relationship, the results indicated that there is a negative, meaningful relationship between these two variables at error level 1 (P
Table 1. Socio-demographic characteristics

\begin{tabular}{|c|c|}
\hline Variable/Variable Levels & No. (\%) \\
\hline \multicolumn{2}{|l|}{ Age } \\
\hline 30 or less & $2(1.9)$ \\
\hline $31-45$ & $40(38.5)$ \\
\hline $46-60$ & $56(53.8)$ \\
\hline 60 or more & $6(5.8)$ \\
\hline \multicolumn{2}{|l|}{ Education } \\
\hline Illiterate & $13(12.5)$ \\
\hline Diploma/under diploma & $76(73.1)$ \\
\hline Associate degree & $5(4.8)$ \\
\hline Bachelor degree & $10(9.6)$ \\
\hline \multicolumn{2}{|l|}{ Income } \\
\hline Less than 300 & $12(11.5)$ \\
\hline $300-500$ & $30(28.8)$ \\
\hline $501-1000$ & $40(38.5)$ \\
\hline More than 1000 & $15(14.4)$ \\
\hline No answer & $7(6.7)$ \\
\hline \multicolumn{2}{|l|}{ Main job } \\
\hline Housewife & $88(84.6)$ \\
\hline Self-employed & 0 \\
\hline Office worker & $16(15.4)$ \\
\hline \multicolumn{2}{|l|}{ Residency } \\
\hline Rural area & $39(37.5)$ \\
\hline Urban area & $65(62.5)$ \\
\hline \multicolumn{2}{|l|}{ Psychologist visit record } \\
\hline Yes & $22(21.2)$ \\
\hline
\end{tabular}

$\leq 0.001$ and $r=0.312$ ) so that as age increases, the sexual function decreases. Besides, the Spearman test result denoted that there is a positive, meaningful relationship between income and sexual function, which means that as income rises, the sexual function improves $(\mathrm{P} \leq 0.05$ and $\mathrm{r}=$ 0.200).The study result on the relationship between other variables including education, family size, surgery period and sexual function did not support any relationship (Table 3).

\section{Discussion}

The findings of this prospective study indicated that the prevalence of sexual dysfunction among Iranian patients with breast cancer was high. Sexual dysfunction outbreak was found to be $87.5 \%$ in 104 studied patients. The present study findings demonstrated that the highest SD 
Table 2. Sexual Dysfunction Dimensions in Breast Cancer Patients ${ }^{\mathrm{a}}$

\begin{tabular}{|c|c|c|c|c|}
\hline Area & & Disorder & No Disorder & Cutoff \\
\hline \multirow[t]{4}{*}{ Sexual disorder (Total scale) } & & $91(87.5)$ & $13(12.5)$ & 28 \\
\hline & Desire & $72(69.2)$ & $32(30.8)$ & 3.3 \\
\hline & Arousal & $67(64.4)$ & $37(35.6)$ & 3.4 \\
\hline & lubrication & $43(41.3)$ & $61(58.7)$ & 3.7 \\
\hline \multirow{3}{*}{ Sexual dimension } & Orgasm & $33(31.7)$ & $71(68.3)$ & 3.4 \\
\hline & Pain & $32(30.8)$ & $72(69.2)$ & 3.8 \\
\hline & Satisfaction & $28(26.9)$ & $76(73.1)$ & 3.8 \\
\hline
\end{tabular}

${ }^{\mathrm{a}}$ Values are expressed as No. (\%).

Table 3. The Correlation of Sexual Function with Demographic Variables

\begin{tabular}{lccc}
\hline Predictor Variable & $\begin{array}{c}\text { Correlation } \\
\text { Coefficient }(\mathbf{r})\end{array}$ & P Value & Correlation Type \\
\hline Age & $-0.312^{\mathrm{a}}$ & 0.001 & Pearson \\
\hline Education & -0.017 & -0.863 & Spearman \\
\hline Family size & 0.037 & 0.712 & Pearson \\
\hline Income & $0.200^{\mathrm{a}}$ & 0.05 & Spearman \\
\hline Surgery period & 0.081 & 0.411 & Spearman \\
\hline${ }^{\mathrm{a}} \mathrm{P}=0.01$. & & & \\
\hline
\end{tabular}

is related to desire (69.2\%) followed by sexual arousal disorder (64.6\%). This finding is in line with those obtained by Mohammadi et al. (23) who investigated the relationship between sexual function disorder and life quality among female patients suffering from uterine, ovarian and breast cancer in Iran .In their research, the SD level has been $61 \%$ in desire and 55\% in arousal.

In our research, there was a positive, significant relationship between income and sexual function a negative and significant relationship between patients' education level, age and sexual dysfunctions, that is, the higher the subjects' education and age are, the less their sexual function is, or in other words, the more they suffer from sexual disorders.

In the study conducted by Barni and Mondin (14), the breast cancer relevant treatment affected individuals' sexual activity, $90 \%$ of the patients followed up their sexual activity after the treatment but many of them have faced with disorder. Lack of sexuality was observed in $64 \%$ of patients, while $48 \%$ experienced lower motivation. Vaginismus, frigidity, vaginal lubrication and dyspareunia were among disorders reported by these patients. Yang et al. (24) in Korea showed that chemotherapy-basedtreated patients with breast cancer have lower sexual ac- tivity and motivation while no relationship was found between patients' sexual function and surgical-based treatments. Bakewell and Volker (13) discovered that all performed therapies on the breast cancer suffering women result in decreased sexual activity. The result of current research regarding high outbreak of disorder in cancerous women is consistent with the results gained by Harirchi et al. (25) and Sbitti et al. (26). Mortimer stated that the most prevalent neoplastic medications used worldwide for breast cancer is tamoxifen. By increased hot flashing, night sweating and vaginal discharge and increased early menopause in women under 45 years old, tamoxifen leads to sexual arousal and reaching orgasm (27). In the current study, $42 \%$ of women have had tamoxifen taking record and $37 \%$ had pre-chemotherapy and $63 \%$ experienced postchemotherapy menopause. Andersen (28) said that surgeries like hysterectomy and mastectomy have significant effects on cancerous women, resulting in dropped sexuality, sexual arousal, increased dyspareunia and disorder in orgasm. Surgery following breast cancer is a factor making the patients pessimistic about their body when compared to other women (29). SFD in breast cancer women in this study compared to the Iranian women from normal population indicates that in breast cancer stricken women, it is highly prevalent. In another research (30) pursuing the goal to determine women's SD outbreak in fertility ages conducted on 250 subjects, the mean total score of sexual function was reported as $27.4 \pm 7.3$ according to FSFI questionnaire; in this research, this score was $21.05 \pm 7.9$ and it was revealed that $64.6 \%$ of the women suffered from SFD. In a study concerning SD and its associated factors on Sabzevar female residents, Bolurian and Ganjloo (31) reported the SD rate as 63.2\%. they suggested that age variable has a meaningful relationship with total sexual function, sexuality, arousal and lubrication .Also, $48 \%$ of the sample in the age bracket under 25 and $85 \%$ over 40 years old suffered from SD in their sexual relation- 
ships. Age variable in other age groups had not a significant relationship with other sexual aspects. Manganiello et al. (32) in their university affiliated to a hospital located in the eastern Brazil denoted that the majority of women with breast cancer (40.48\%) regularly got unfavorable score in sexual quotient (SQ-F).A positive, meaningful relationship was observed between SQ-F and education and sub-dimensions of functional capacity, vitality ,emotional limitations and psychological health. Also, a negative, meaningful relationship was found between SQ-F and sexual partner's age .The average SQ-F was significantly higher among the women undergoing breast reconstruction (BR) operation. Women with breast cancer in Australia indicated that breast cancer can have meaningful effects on both sexuality, psychosocial, and physical dimensions of women (19). In the post-mastectomy women's body image dimensions, Moreira and Canavarro (33) demonstrated that only modesty has grown over time among the subjects. Generally, the prediction of post-mastectomy and post-surgery body image dimensions has accompanied with higher modesty and lower appearance-related contentment. Bakht and Najafi (34) stated that there was no significant statistical difference between breast cancer sufferers and healthy ones in terms of sum scores of sexual function, whereas a meaningful difference was found between both groups in sexuality, arousal, sexual satisfaction, and pain .The results did not reveal any meaningful difference in the subscales of vaginal lubrication, and orgasm between the two groups. The findings of Fallbjork et al. (35) in Sweden suggested that slight significant changes were seen in the breast cancer patients' body image during a 2 year interval between the ending of the first questionnaire (10 months after mastectomy) and the second questionnaire (2 years after mastectomy). An exception was about the meaningful decrease in sexual appeal and comfort over the intercourse. In this follow-up, $21 \%$ of these women were undergone breast reconstruction. They have been significantly younger than the women not undergoing BR. No other significant difference was discovered between these two groups of women except in terms of age. The fact that lower sexual appeal and comfort in intercourse has been found in BR women group may be surprising. Studying in Turkey, Bektas and Ozkan (36) achieved the results indicating that post-operation body image has been more problematic for women undergoing mastectomy than those having surgery with preserving breast. It seems that the psychological complications have influenced women's sexual function more that the physiological factors because in the majority of the reported studies, the most common sexual problem has been sexuality and arousal .This dimension mainly reflects their psychological status and conditions while the dimensions like sexual stimulation ,vaginal moisture and dyspareunia are caused due to physiological disorders (9). In this research, the most common sexual problem has been found in the sexuality and sexuality arousal dimension. Based on the obtained results, the sexual satisfaction dimension has had a better function than other sexual dimensions .About studying the significance and outbreak of various sexual disorder dimensions, the present research results are different from those obtained by Safarinejad et al. (37). People usually feel ashamed to talk about their sexual affaires and this can bring about contradiction in various studies. In short, it can be claimed that many factors can affect women's sexual issues out of which women's values, beliefs, and expectations can be pointed out (38). A wide variety of sexual problems outbreak rates exist in breast cancer sufferers that may relate to their treatment type. The results derived from this research show that various treatment methods have had no influence on the patients' sexual function, differing from the other researchers' findings. The study result obtained by Sbitti et al. (26) indicated that $90 \%$ cases of post-chemotherapy, $9 \%$ of post-surgery, and $3 \%$ of post-radiotherapy showed no disorder getting started with hormone therapy. In the findings obtained by Thors et al. (39), the subjects with chemotherapy have displayed more intense function disorder while those with hormone therapy had been less affected by function disorders. Safarinejad et al. (37) also mentioned the impact of therapy on disorder level. The results of their study implied that radiotherapy, chemotherapy, and hormone therapy have caused 6 times increase in vaginal moisture and satisfaction disorders. The reason behind the difference between the frequencies obtained in this study and those of other studies may relate to the applied methods, demographic characteristics, and selecting different medical approaches towards the patients. One of the reasons for the incompatibility of the results of the present research results with other ones may be originated from the sample size. In addition, individual, cultural, and racial differences can be some of the probable reasons in this context. This is because, based on different reports, Asian females compared with women in western countries, have reported higher sexual function disorders $(33,40)$. It is not possible to compare the present study with those conducted in other countries, since cultural, social, economic, and ethical discrepancies can have a great effect on sexual behaviors (14).

\subsection{Limitations}

This research faced some limitations. For instance, the patient's psychological and mental conditions have been effective in answering some questions. Lack of easy access to the patients was among the other limitations. Be- 
cause of the novelty of the work, identical research on this subject was rare to be compared with our research. The obtained results have to be interpreted cautiously due to the constraints of the employed methodology. It seems that the sample size was too small to allow the generalizability of the results to a larger population. The questionnaire provides the subjective interpretation of the problems while it does not pave the ground for real clinical diagnosis. However, this study displays a problem as big as that necessitates deeper research.

\subsection{Recommendations}

It is recommended to carry out a similar study with a control group designed as pre-test/post-test on a larger population in order to study the effect of breast cancer itself.

\subsection{Conclusion}

Having knowledge about SD changes dimension seems essential in order to diagnose and treat cancer stricken ones. Health care providers can consult with a consultant ahead of the surgery on breast cancer in order to get informed about the patient's opinions and their problems in their sexual relations as well as to present some information to the patient about the surgery type and limitations induced by the treatment and help her with sexual rehabilitation after the surgery .To adopt strategies for appropriate interventions ,training and consultation is recommended in order to promote the cancer sufferers' sexual health. When designing the breast cancer treatment plan, the physician should discuss with patient about sexual function disorders as a part of probable side effects of the surgery. This is because healthy sexual activity is considered as one of the vitality and health indices and this activity should be kept in mind as much as possible. This helps the patient cope with and adjust to the disease as a debilitating malady. Although, many cases are unknown, the recent studies strongly support this idea that analyzing and managing sexual problems should be a standard part of clinical care of breast cancer-treated women.

\section{Acknowledgments}

Finally, we would like to appreciate the chancellor of Mazandaran University of Medical Sciences, Tooba postspecialized clinic officials in Sari and the others for their sincere cooperation in performing this research .It is worthy to mention that the present paper is a part of the student's master dissertation.

\section{Footnotes}

Authors' Contribution: Samira Abdollahi Chirani designed the study, performed the literature review and prepared the manuscript. Forouzan Elyasi designed the study, managed the study, wrote the paper, designed the search strategy and reviewed literature. Bahram Mirzaian participated in the design of the search strategy and literature review. All authors read and approved the final manuscript.

Financial Disclosure: None declared.

Funding/Support: None declared.

\section{References}

1. Jamalian R. Information about Radiology and Oncology. The fight against cancer. [in Persian]. Tehran: Pharos; 1998.

2. Chen PY, Chang HC. The coping process of patients with cancer. Eur J Oncol Nurs. 2012;16(1):10-6. doi: 10.1016/j.ejon.2011.01.002. [PubMed: 21376664].

3. Ministry of Health and Medical Education. National Report on Cancer Registration. [in Persian]. ; 2007.

4. Noorani S, Jonaidy E, Shakeri MT, Mokhber N. Comparison of Quality of life in Fertile and Infertile Women Referred to the Public Clinics in Mashhad. [in Persian]. IJOGI. 2012;15(7):24-31. doi: 10.22038/ijogi.2012.5717.

5. Bober SL, Varela VS. Sexuality in adult cancer survivors: challenges and intervention. J Clin Oncol. 2012;30(30):3712-9. doi: 10.1200/JCO.2012.41.7915. [PubMed: 23008322].

6. Krebs LU. Sexual health during cancer treatment. Adv Exp Med Biol. 2012;732:61-76. doi:10.1007/978-94-007-2492-1_5. [PubMed: 22210252].

7. Schover LR. Sexuality and fertility after cancer. New York: John Wiley \& Sons; 1997

8. Dennerstein L, Dudley EC, Hopper JL, Burger H. Sexuality, hormones and the menopausal transition. Maturitas. 1997;26(2):83-93. [PubMed: 9089557].

9. Mohammadi K, Rahnama P, Moayed S, Faghihzadeh S, Sahraian MA Mohammaditabar S, et al. Sexual dysfunction and predisposing factors in women with multiple sclerosis. [in Persian]. Payesh. 2013;12:717.

10. American Cancer Society. Sexuality and Cancer: For the Woman with Cancer and Her Partner. Atlanta: American Cancer Society; 2015.

11. Gahanfar SH, Molayinejad M. Text book of Sexual dysfunction. Tehran: Salemi Publishing; 2002.

12. Anllo LM. Sexual life after breast cancer. $J$ Sex Marital Ther. 2000;26(3):241-8. doi: 10.1080/00926230050084632. [PubMed: 10929572].

13. Bakewell RT, Volker DL. Sexual dysfunction related to the treatment of young women with breast cancer. Clin J Oncol Nurs. 2005;9(6):697702. doi: 10.1188/05.CJON.697-702. [PubMed: 16381545].

14. Barni S, Mondin R. Sexual dysfunction in treated breast cancer patients. Ann Oncol. 1997;8(2):149-53.

15. Fobair P, Stewart SL, Chang S, D’Onofrio C, Banks PJ, Bloom JR. Body image and sexual problems in young women with breast cancer. Psychooncology. 2006;15(7):579-94. doi: 10.1002/pon.991. [PubMed: 16287197].

16. Parker PA, Youssef A, Walker S, Basen-Engquist K, Cohen L, Gritz ER, et al. Short-term and long-term psychosocial adjustment and quality of life in women undergoing different surgical procedures for breast cancer. Ann Surg Oncol. 2007;14(11):3078-89. doi: 10.1245/s10434-0079413-9. [PubMed: 17574501]. 
17. Han J, Grothuesmann D, Neises M, Hille U, Hillemanns P. Quality of life and satisfaction after breast cancer operation. Arch Gynecol Obstet. 2010;282(1):75-82. doi: 10.1007/s00404-009-1302-y. [PubMed: 19960349].

18. Lam WW, Li WW, Bonanno GA, Mancini AD, Chan M, Or A, et al. Trajectories of body image and sexuality during the first year following diagnosis of breast cancer and their relationship to 6 years psychosocial outcomes. Breast Cancer Res Treat. 2012;131(3):957-67. doi: 10.1007/s10549-011-1798-2. [PubMed: 21971728].

19. Gilbert E, Ussher JM, Perz J. Sexuality after breast cancer: a review. Maturitas. 2010;66(4):397-407. doi: 10.1016/j.maturitas.2010.03.027. [PubMed: 20439140].

20. Panjari M, Bell RJ, Davis SR. Sexual function after breast cancer. J Sex Med. 2011;8(1):294-302. doi: 10.1111/j.1743-6109.2010.02034.x. [PubMed: 21199377].

21. Cardoso F, Loibl S, Pagani O, Graziottin A, Panizza P, Martincich L, et al. The European Society of Breast Cancer Specialists recommendations for the management of young women with breast cancer. Eur J Cancer. 2012;48(18):3355-77. doi: 10.1016/j.ejca.2012.10.004. [PubMed: 23116682].

22. Mohammadi M, Heidari M, Faghihzadeh $\mathrm{S}$. The female sexual function index: validation study of the Iranian version. [in Persian] Payesh. 2009;7:269-78.

23. Mohammadi SZ, Ghaffari F. Sexual dysfunction and its correlation with quality of life among women affected with cancer. [in Persian] Iran J Obstetrics Gynecol Infertil. 2009;12(2):39-46.

24. Yang EJ, Kim SW, Heo CY, Lim JY. Longitudinal changes in sexual problems related to cancer treatment in Korean breast cancer survivors: a prospective cohort study. Support Care Cancer. 2011;19(7):909-18. doi: 10.1007/s00520-010-0885-y. [PubMed: 20419495].

25. Harirchi I, Montazeri A, Zamani Bidokhti F, Mamishi N, Zendehdel K. Sexual function in breast cancer patients: a prospective study from Iran. J Exp Clin Cancer Res. 2012;31:20. doi: 10.1186/1756-9966-31-20. [PubMed: 22405489].

26. Sbitti Y, Kadiri H, Essaidi I, Fadoukhair Z, Kharmoun S, Slimani K, et al. Breast cancer treatment and sexual dysfunction: Moroccan women's perception. BMC Womens Health. 2011;11:29. doi: 10.1186/1472-6874-1129. [PubMed: 21668971].

27. Mortimer JE, Boucher L, Baty J, Knapp DL, Ryan E, Rowland JH. Effect of tamoxifen on sexual functioning in patients with breast cancer.J Clin Oncol. 1999;17(5):1488-92. [PubMed:10334535].
28. Andersen BL. Yes, there are sexual problems. Now, what can we do about them?. Gynecol Oncol. 1994;52(1):10-3. doi: 10.1006/gyno.1994.1003. [PubMed: 8307494].

29. Ferrari PA. Psychosexual sequence of gynecological condition. J Sex Marit Ther. 1994;9:239-49.

30. Bahrami N, Alizadeh S, Bahrami S. Sexual dysfunctions and associated factors in women of reproductive age. [in Persian].J Shahid Beheshti School Nurs Midwifery. 2012;21(75z).

31. Bolurian Z, Ganjloo J. Evaluating sexual dysfunction and some related factors in women attending Sabzevar health care centers. [in Persian]. J Reprod Infertil. 2007;10(2):163-70.

32. Manganiello A, Hoga LA, Reberte LM, Miranda CM, Rocha CA. Sexuality and quality of life of breast cancer patients post mastectomy. Eur J Oncol Nurs. 2011;15(2):167-72. doi:10.1016/j.ejon.2010.07.008. [PubMed: 20864400].

33. Moreira H, Canavarro MC. A longitudinal study about the body image and psychosocial adjustment of breast cancer patients during the course of the disease. Eur J Oncol Nurs. 2010;14(4):263-70. doi: 10.1016/j.ejon.2010.04.001. [PubMed: 20493769].

34. Bakht S, Najafi S. Body image and sexual dysfunctions: comparison between breast cancer patients and healthy women. Proc Soc Behav Sci. 2010;5:1493-7.

35. Fallbjork U, Rasmussen BH, Karlsson S, Salander P. Aspects of body image after mastectomy due to breast cancer - a twoyear follow-up study. Eur J Oncol Nurs. 2013;17(3):340-5. doi: 10.1016/j.ejon.2012.09.002. [PubMed: 23083641].

36. Bektas H, Ozkan I. P66 Sexual dysfunction in breast cancer. Eur J Oncol Nurs. 2010;14:S43. .

37. Safarinejad MR, Shafiei N, Safarinejad S. Quality of life and sexual functioning in young women with early-stage breast cancer 1 year after lumpectomy. Psychooncology. 2013;22(6):1242-8. doi: 10.1002/pon.3130. [PubMed: 22777952].

38. Hasanzadeh Bashtian M. Effective factors on women sexuality. IJOGI. 2005 Dec:86-92.

39. Thors CL, Broeckel J, Jacobsen PB. Sexual functioning in breast cancer survivors. Cancer Control. 2001;8(5):442.

40. Laumann EO, Nicolosi A, Glasser DB, Paik A, Gingell C, Moreira E, et al. Sexual problems among women and men aged $40-80 \mathrm{y}$ : prevalence and correlates identified in the Global Study of Sexual Attitudes and Behaviors. Int J Impot Res. 2005;17(1):39-57. doi: 10.1038/sj.ijir.3901250. [PubMed: 15215881]. 